\title{
Teachers Knowledge Mobilized in Geometry Lessons and Contingency Situations
}

\author{
Bárbara Silva Gumiero ${ }^{1 *}$ (D) , Vinícius Pazuch ${ }^{1}$ (1D
}

${ }^{1}$ Universidade Federal do ABC (UFABC), BRAZIL

*Corresponding Author: barbaragumiero@gmail.com

Citation: Gumiero, B. S., \& Pazuch, V. (2021). Teachers Knowledge Mobilized in Geometry Lessons and Contingency Situations. International Electronic Journal of Mathematics Education, 16(1), em0620. https://doi.org/10.29333/iejme/9371

\begin{tabular}{|c|c|}
\hline ARTICLE INFO & ABSTRACT \\
\hline Received: 26 Mar. 2020 & Mathematics classes have contingency situations in the relationship established between teacher and students. \\
\hline Accepted: 22 Oct. 2020 & $\begin{array}{l}\text { The objective of the article is to understand the dimensions of the teacher's knowledge that are constituted in the } \\
\text { development/execution of tasks on geometric concepts in interaction with students. For this, a collaborative group } \\
\text { of two teachers and two master's students elaborated four tasks on geometric concepts, which were } \\
\text { developed/executed by the participating teachers in their respective classes. Both classes were recorded in audio } \\
\text { and video and analyzed based on the Knowledge Quartet (KQ). KQ is a theoretical analysis tool comprizing four } \\
\text { dimensions - foundation, transformation, connection and contingency. According to the data, contingency was } \\
\text { found to be a prominent dimension, which led the analysis to be focused on that dimension. The teachers } \\
\text { mobilized knowledge related to all contingency codes, which culminated in a deviation from the agenda. The } \\
\text { teachers involved had insights due to the (in) availability of resources. The contingency moments caused by the } \\
\text { students started from an idea or an unexpected difficulty, which expanded the KQ codes already identified. }\end{array}$ \\
\hline
\end{tabular}

Keywords: tasks, knowledge quartet, geometry teaching

\section{INTRODUCTION}

This article is part of a multipaper dissertation aimed to investigate the teaching knowledge mobilized by teachers who teach mathematics. In one of the articles, we investigated this kind of knowledge in relation to the planning stage of tasks on geometric concepts. In this study, we will address the development/execution of those tasks in the classroom. We know that any task or class must be well planned to be effective. However, considering that teaching involves working with (unpredictable) human beings unlike professions that work with inanimate objects such as machines, paper, etc. - teachers cannot plan everything, since it is not possible to predict all events in a classroom.

In this article, we seek to discuss the knowledge mobilized by teachers when developing/performing geometry tasks in the interaction with students of the final years of elementary school (corresponding to the middle school in the U.S.). However, we do not seek here to mention the amount of knowledge a person should have to be a teacher, as we cannot define what a necessary knowledge would be for that (Browning et al., 2014).

In this sense, Rowland, Huckstep, and Thwaites (2005) developed a theoretical analysis tool called Knowledge Quartet (KQ), that seeks to identify this knowledge mobilized by teachers, without intending to list the necessary knowledge. The KQ was developed from the very practice and is composed of four dimensions that characterize teaching knowledge, one of which is contingency, which is identified in unpredictable and unplanned situations that happen in the classroom.

Thus, when discussing teacher knowledge based on the KQ and with emphasis on the contingency dimension, we aim to understand the dimensions of teacher knowledge that constitute the development/execution of tasks on geometric concepts in interaction with the students. Next, we will discuss professional teaching knowledge and contingency as a component of that knowledge.

\section{CONTINGENCY: A DIMENSION OF TEACHING PROFESSIONAL KNOWLEDGE}

The classroom is a heterogeneous environment, composed of several people with different thoughts, opinions and feelings. Thus, it is a favorable environment for unpredictable events. One of the attributions of a teacher is the planning of classes and 
tasks, however it is not always possible to ensure that the whole planning will be met. When planning faces an unexpected conundrum, it is called a contingency moment (Rowland, Huckstep, \& Thwaites, 2005).

Stein and Smith (1998) characterize tasks as a "segment of classroom activity dedicated to the development of a particular mathematical idea" (p. 22), taking place in one class at most. When developing those tasks, teachers elaborate investigative situations, in which, once again, the answers, ideas and/or strategies used by students cannot be predicted. In this way, teachers also mobilize knowledge related to contingency when developing tasks in the classroom, in addition to knowledge focused on content and pedagogy.

Studies on teaching professional knowledge gained prominence from Shulman $(1986,1987)$ and his classification of teaching knowledge, regardless of the curricular component or the level of education in which the teacher works. After that, other studies were developed in this area, focusing specifically on mathematics (Ball, Thames, \& Phelps 2008; Rowland, Huckstep, \& Thwaites, 2005).

One of them was the Knowledge Quartet (KQ), a theoretical analysis tool that emerged from the very practice to establish dimensions of the teacher's knowledge. Four dimensions were established - foundation, transformation, connection and contingency - for teachers to use when reflecting on their classes, identifying the knowledge mobilized. The objective of the KQ was not to list the necessary and mandatory knowledge for the teaching professional, but rather to provide a theoretical analysis tool used in discussions between teachers, between teacher educators and teachers in training or even individually. Each of these dimensions is composed of codes, which are actions that characterize the dimensions (Rowland, Huckstep, \& Thwaites, 2005).

The foundation dimension represents the knowledge already internalized by the teachers, developed throughout their training. This dimension brings codes about the knowledge of mathematics and Mathematics Education. Transformation is related to the very transformation of the knowledge that the teacher has into the knowledge that students will work in the classroom. Thus, the codes address examples, representations and materials that will be used by the teacher (Rowland, 2013).

In connection, the sequence and processes that the teacher decides to approach when developing certain content is discussed. Finally, we have the contingency dimension, the focus of this article, which is characterized as the ability to respond convincingly to unpredictable situations. The codes that make up this dimension are response to students' ideas; deviation from the planned agenda; teachers' insights; and (in) availability of resources (Rowland, 2013).

We understand that this knowledge is mobilized in the classroom. However, the foundation, transformation and connection dimensions can be planned and are generally discussed in the initial and continuing education. Contingency proves to be a dimension of the practice itself, for which classroom situations cannot be predicted.

However, we reaffirm the fundamental role of planning, as it is the basis for teachers to identify possible errors, suggestions and ideas that may arise during class. In addition, we highlight that studies on contingency situations in initial and continuing education, either through teachers' reports or videos, are needed. In this way, future teachers, upon knowing those situations, can expand the possibilities of understanding teaching practice, highlighting contingency moments.

Rowland, Thwaites, and Jared (2015) carried out a study specifically on the contingency dimension, which guided this research. They investigated the factors that can trigger those contingency moments, namely: the students, the teachers or the resources.

When contingency comes from students, it relates to the responses to the students' ideas, that is, how the teacher reacts to those ideas. According to the authors, the teacher can either ignore it; or recognize the student's idea, but not incorporate it into the discussion; or recognize and incorporate the idea into the classroom discussion. Students' ideas can appear in three ways: (a) when answering a question the teacher asked; (b) when responding spontaneously in a discussion; (c) when answering incorrectly, either to a question or a discussion (Rowland, Thwaites, \& Jared, 2015).

In the case of the contingency triggered by the teacher him/herself, we have a relationship with the teachers' insight code. The contingency, in this sense, arises from the teacher's reflection while developing/executing the task or class. It may be something new that brings improvements to the development/execution of that task (a new idea or a new resource that he/she decides to use). Also, as the teacher realizes that a specific exercise, discussion and or explanation will cause students' misconception and then, he/she decides to change what was planned (Rowland, Thwaites, \& Jared, 2015).

The last triggering factor of the contingency would be the resources the teacher uses, characterized in the (in)availability of resources code. Thus, this contingency is identified when the teacher gets prepared to use a certain resource, but it becomes unavailable for some reason, or when the teacher chooses to use an available resource during class without having planned its use in advance (Rowland, Thwaites, \& Jared, 2015).

In Figure 1 we present a scheme with the three triggering factors of contingency and their respective consequences that we elaborated based on the studies of Rowland, Thwaites and Jared (2015). Each shade of blue used in the scheme represents a factor, for example, the tags in darker blue represent actions of students as a result of what happens in the classroom.

In view of the justifications and theoretical assumptions constructed, we present now the methodological procedures of this research. 


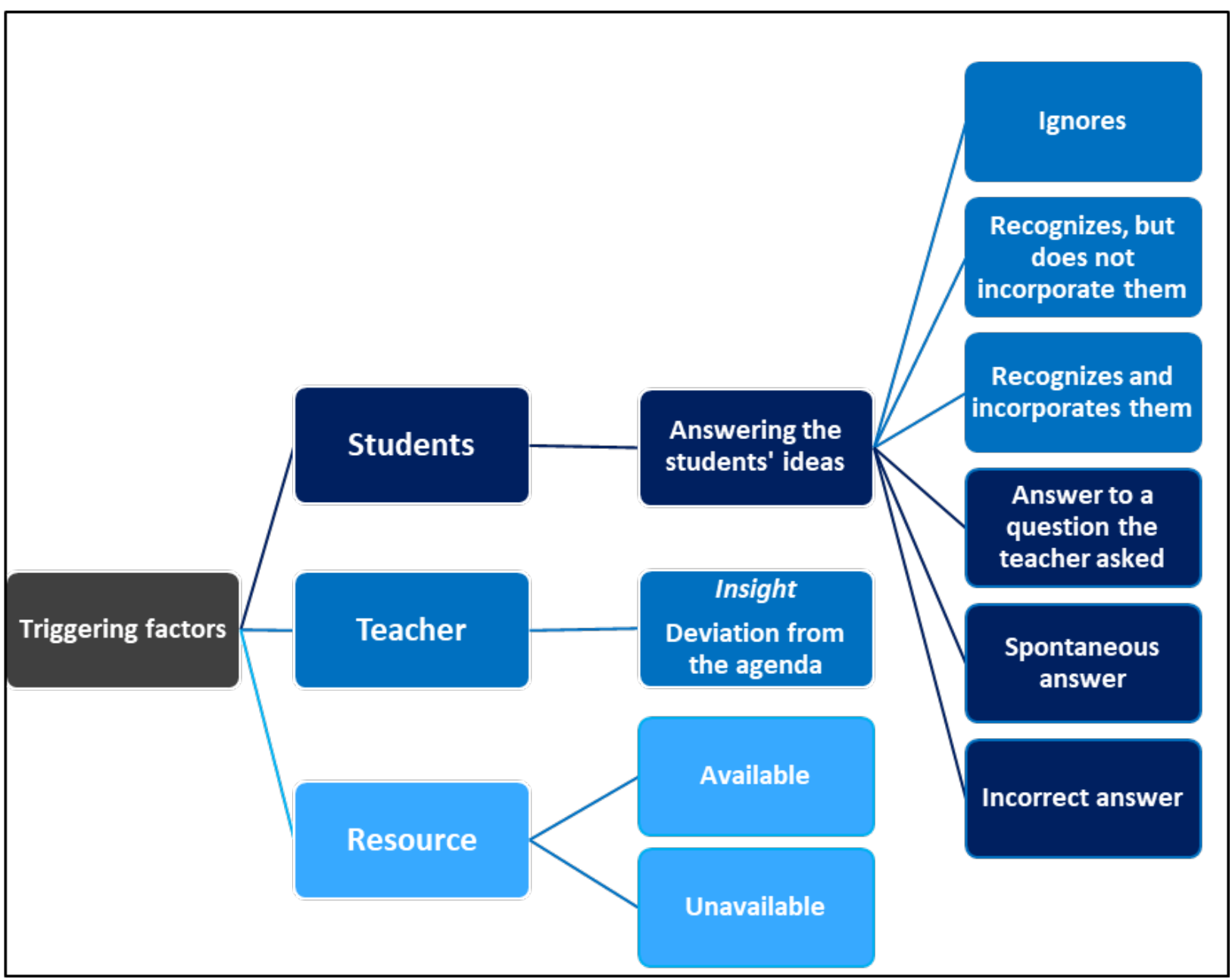

Figure 1. Contingency triggering factors

\section{METHODOLOGICAL PROCEDURES}

Throughout this research, we formed a collaborative group in a state school located in the city of Santo André (SP). Four mathematics teachers from that institution were invited to participate in the group, however, due to the availability of schedules and personal interests, only two teachers accepted to participate ${ }^{1}$. In addition, the author of this article and a master's student also participated in the research.

The objective was to provide a training environment in, for and with the school. In this way, the discussions in the group were focused on school situation, and the teachers were also responsible for their training. Seven meetings were held for planning and reflection on geometry tasks for the middle school, plus three classes for the development/execution of tasks in the classroom, between March and May 2019. In this article, we will only address the development/execution of tasks in the classroom.

We will give the participating teachers the fictitious names Teacher Ana and Teacher Beatriz. Both worked with the 9th grade in the same school, also teaching in other state and/or municipal schools in the city of São Paulo. The teachers had experience in other areas, such as physics, and in other segments, such as Early Childhood Education. In addition to a degree in mathematics, they had other teaching trainings. Teacher Ana attended a teaching degree while Teacher Beatriz studied pedagogy, and both attended a degree in Mathematics.

Three classes were devoted to the development/execution of geometry tasks with the students of the 9th grade, with which both teachers worked. Those classes were preceded by meetings for planning and followed by meetings for them to reflect on the practice.

We developed four tasks collaboratively. The group was able to give suggestions and ideas and, after planning was completed, the teachers developed the tasks in the classroom. The classes were recorded in audio and video, in a total of eight classes recorded and analyzed by the researchers.

In group meetings with collaborative characteristics, we defined that the tasks developed would be related to the unity of geometry. The teachers stated that they were not very familiar with this thematic unit, but they were interested in learning the 


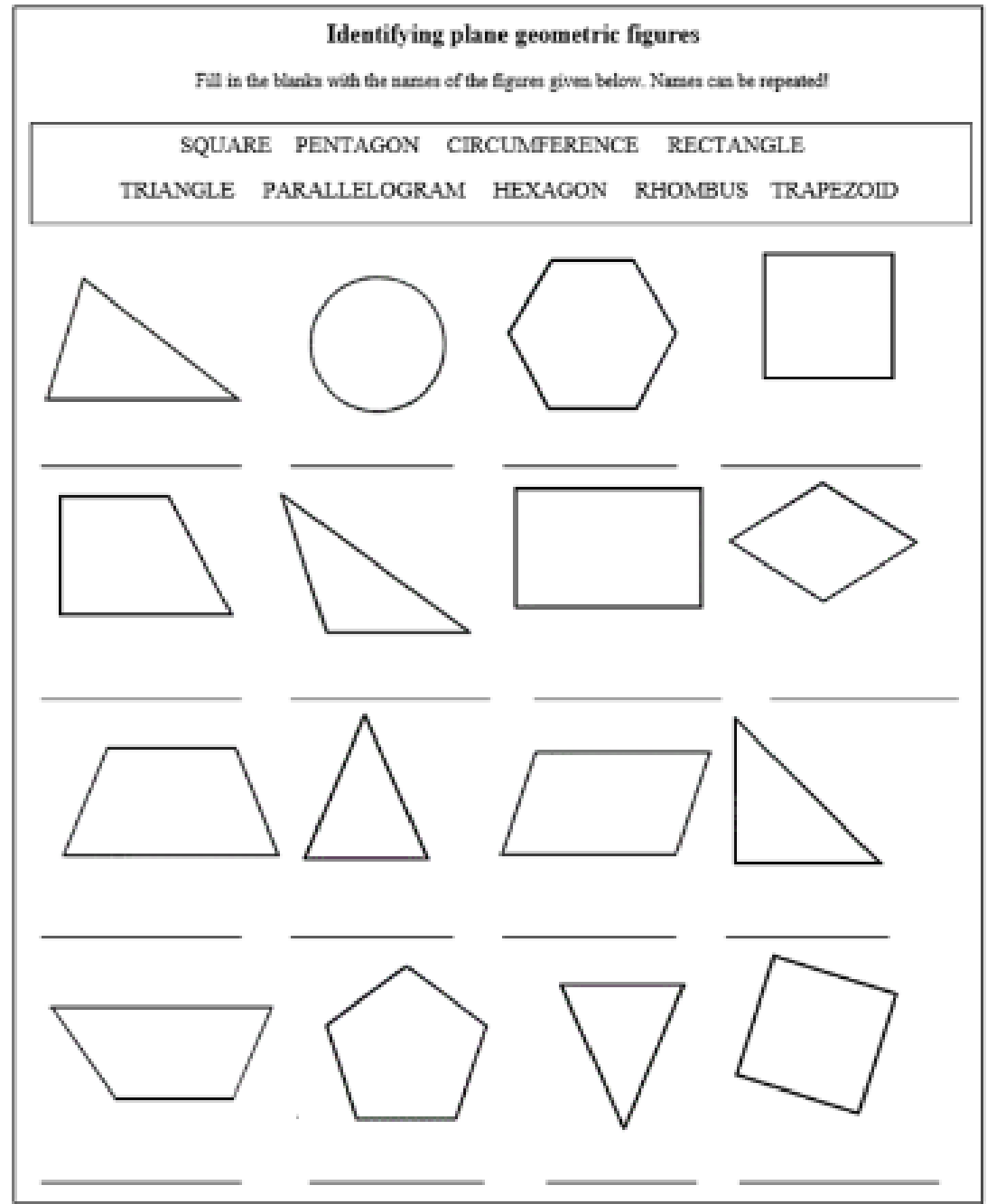

Figure 2. Task 1

content and developing geometry tasks with the students, starting from the simplest notions, even though they were not recommended for the 9th grade, according to the Base Nacional Comum Curricular ${ }^{2}$ (BNCC).

At the group's second meeting, we discussed the structure of BNCC and its implementation in schools. Therefore, we used the skills and competences covered in this document as guidelines to elaborate the tasks.

The first two tasks addressed the content of plane figures and then the quadrilaterals in specific, aiming at the following skills: EF03MA15 - "Recognizing, comparing and naming plane figures (circle, square, rectangle and triangle), through common characteristics, in drawings presented in different layouts or in geometric solids" (Brasil, 2018, p. 283) and EF06MA20 -" Identifying characteristics of quadrilaterals, classifying them in relation to sides and angles and recognizing the inclusion and intersection of classes among them" (Brasil, 2018, p. 303).

The other two tasks dealt with geometric solids and planning, guided by skills: EF04MA17 - "Associating prisms and pyramids with their design, and analyzing, naming and comparing their attributes, establishing relationships between plane and spatial representations" (Brasil, 2018, p. 293); EF05MA16 - "Associating spatial figures with their design (prisms, pyramids, cylinders and cones) and analyzing, naming and comparing their attributes" (Brasil, 2018, p. 297) and EF05MA17 - "Recognizing, naming and comparing polygons, considering sides, vertices and angles, and drawing them, using drawing material or digital technologies" (Brasil, 2018, p. 297).

Tasks 1, 2, 3 and 4, elaborated in the group with collaborative characteristics, are presented below.

We seek to investigate the knowledge mobilized by teachers when developing geometry tasks in the final years of elementary school. In this sense, we produced the data at the school where the teachers worked and analyzed the process, as we consider it as important as the product. With these characteristics, we considered the qualitative approach as the most appropriate (Borba \& Araújo, 2019).

2 The BNCC is a normative document that defines essential learning for students of Basic Education and serves as a national reference for the formulation of curricula (BRASIL, 2018). 


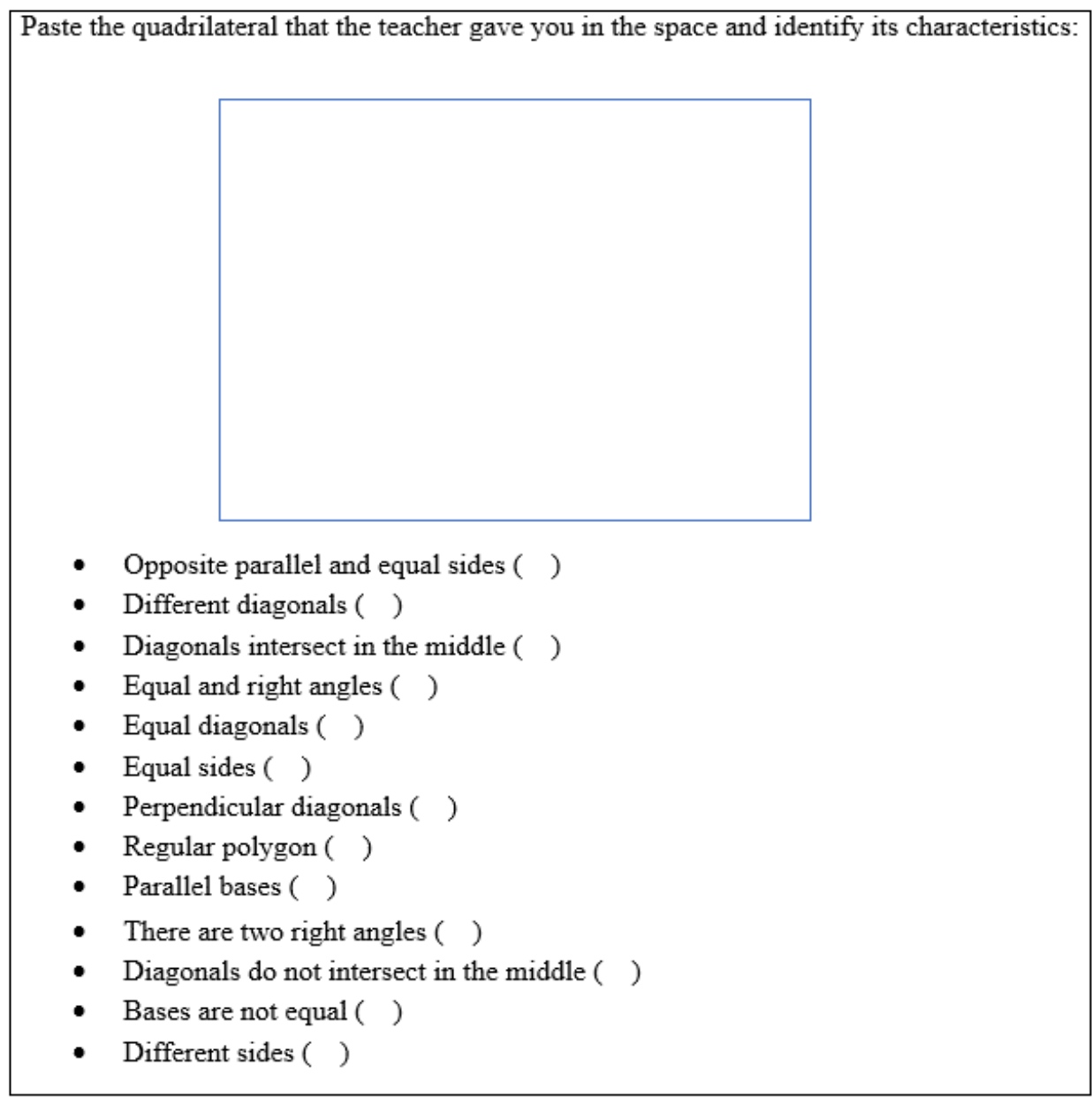

Figure 3. Task 2

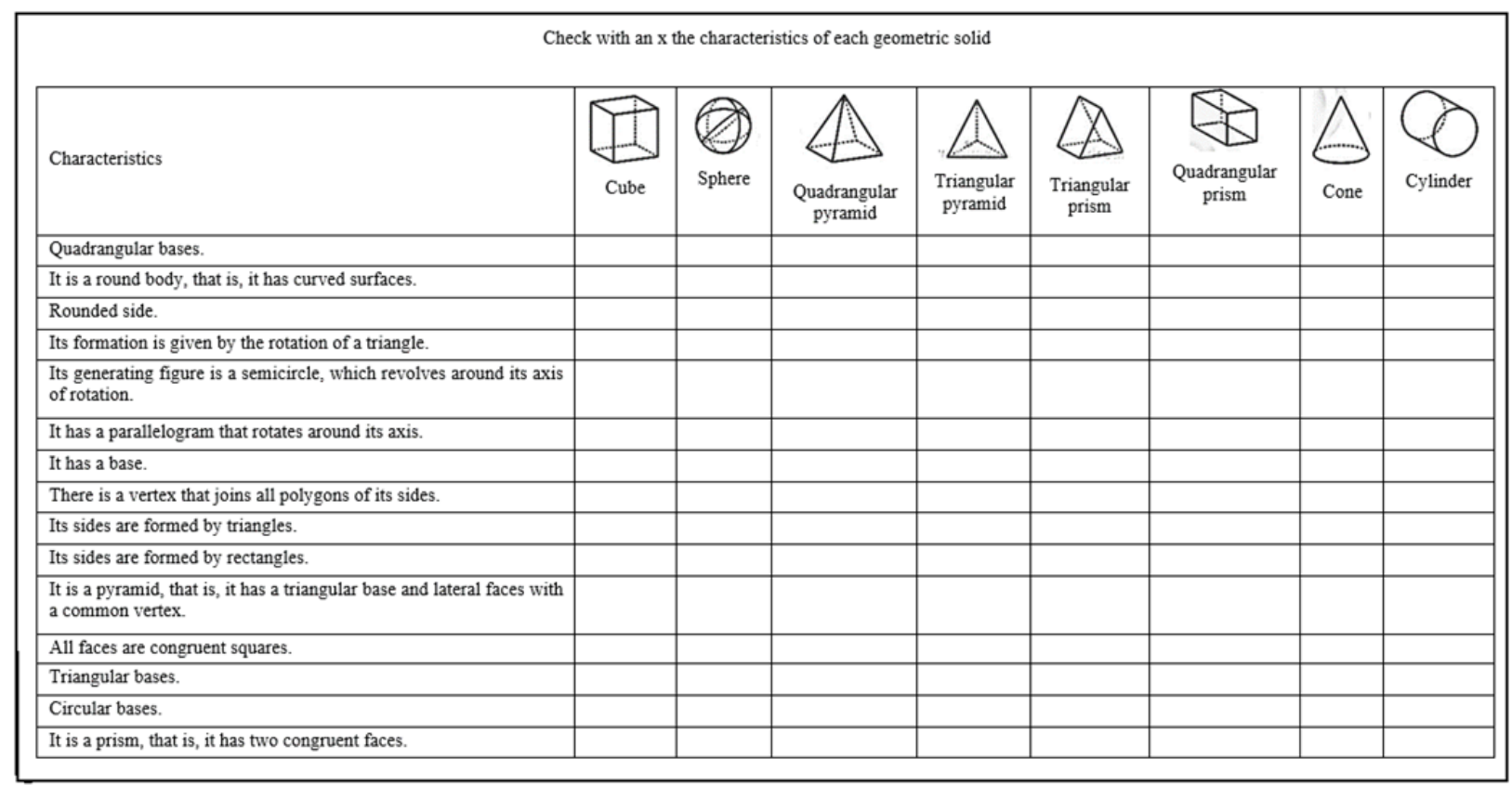

Figure 4. Task 3

For data production, we used audio and video recordings of classes developed by participating teachers. These recordings were transcribed aiming to identify critical events throughout the classes, that is, events that would indicate answers to the research questions, confirming or not the initial hypotheses (Powell, Francisco, \& Maher, 2004).

In total, 96 critical events were identified, 40 events related to Tasks 1 and 2, and 56 related to Tasks 3 and 4 . These events were identified together with the master's student, also involved with the collaborative group. The critical events were discussed in the group reflection meetings. 


\section{GEOMETRY ACTIVITY}

Observe the solid you received and answer:

1. Which plane figures does your solid have?

A:

2. Which solid do you think you will form?

A:

Assemble your solid

- Now that you have assembled your geometric solid, answer:

3. What is the name of your solid?

A:

4. What is the number of:

a) Faces:

b) Vertexes:

c) Edges:

5. Where can we find this solid in our daily lives?

A:

Draw and paint your solid

Figure 5. Task 4

Table 1. Number of sections classified by dimension

\begin{tabular}{ccc}
\hline Dimension & Number of sections \\
\hline Foundation & 76 \\
\hline Transformation & 13 \\
\hline Connection & 18 \\
\hline Contingency & 29 \\
\hline TOTAL & $\mathbf{1 3 6}$ \\
\hline
\end{tabular}

After that, we analyzed each section of the critical events to categorize them in the dimensions and codes of the KQ, as can be seen in Table 1. Some sections were categorized into more than one code and/or dimension, which caused a repetition in the results.

Due to the large number of data produced and, consequently, critical events analyzed, it would not be possible to present and discuss all sections and critical events. Therefore, we chose to analyze only the contingency dimension, addressing unexpected events and the mobilization of knowledge at these times. As Rowland, Huckstep, and Thwaites (2005) define, contingency relates to the ability to respond to unpredictable events in a convincing manner, which commonly occurs in the classroom environment.

To discuss the knowledge mobilized in the contingency, we transcribe some excerpts from the critical events identifying the codes of this dimension. We analyze the excerpts based on the factors that trigger contingency events (student, teacher, or resource) (Rowland, Thwaites, \& Jared, 2015) and their respective consequences. 


\section{DATA ANALYSIS AND DELIMITATION OF THE RESULTS}

The data will be grouped by themes, which may contain one or more critical events. In each of them, we will discuss the main points identified in the critical events through the KQ. The transcript ${ }^{3}$ of the events is presented in turns named "Critical Event" and numbered sequentially. In addition, the codes identified and the factor that triggered the contingency event in the shifts are presented.

\section{Theme 1: Resources}

The teachers planned to use some resources in the development/execution of the tasks. For Task 1, Teacher Beatriz prepared a poster containing the geometric figures and their respective names to help her in the moment of correction. However, when putting the poster on the blackboard with the assistance of the graduate student, Teacher Beatriz realized that her adhesive tape was bad, so the poster was not sticking as she expected.

Critical Event 1

\begin{tabular}{|l|c|c|}
\hline Shift & Code identified & Triggering factor \\
\hline [01] E1: Teacher, I can't see it. & & \\
\hline [02] E2: Neither can I. & $\begin{array}{c}\text { Response to students' } \\
\text { ideas }\end{array}$ & Student \\
\hline [03] TB: Easy, guys. & $\begin{array}{c}\text { (In)availability of } \\
\text { resources }\end{array}$ & Resource \\
\hline The teacher reinforces the tape on the poster, but it does not stick. & $\begin{array}{l}\text { Reviation from the } \\
\text { schedule planned }\end{array}$ & Resource \\
\hline [04] TB: E3, please go to the coordination and ask them for that sticking tape. \\
\hline $\begin{array}{l}\text { Students TB: Complain that Student 3 will take too long to return. } \\
\text { not want to collaborate... no problem. }\end{array}$
\end{tabular}

(Teacher Beatriz's classroom - Task 1 - 04/11/2019)

In Teacher Ana's class, the students also complained about not seeing what was written on the poster.

Critical Event 2

\begin{tabular}{|l|l|l|}
\hline Section & Code identified & Triggering factor \\
\hline [06] E4: Teacher, we can't see. & & \\
\hline [07] TA: What? & & \\
\hline [08] E4: I can't see & & \\
\hline [09] TA: Can't you see? & & \\
\hline [10] E4: No, I can't. & & \\
\hline [11] E5: Go to the front. & & \\
\hline [12] TA: Come here. Sit here, sweetie. & $\begin{array}{c}\text { Response to students' } \\
\text { ideas }\end{array}$ & Students. \\
\hline
\end{tabular}

(Teacher Ana's classroom - Task 1 - 04/11/2019)

Thus, we realized in shift [04] that, although the main resource (poster) was available, other resources were not available. This unavailability of the resource (sticking tape) ended up influencing the planning, diverting them from the agenda (shift [05]). Regarding the fact of seeing the poster, we identified that it was a contingency moment caused by the students themselves and each teacher responded to their ideas in a different way. Among the three types of response, we observed that students responded spontaneously to this situation and, while Teacher Beatriz ignores it (shift [03]), Teacher Ana recognizes and responds to the student's request (shift [12]).

We also observed that at the end of Task 1 Teacher Ana would remove the poster to start the next task. However, she has an insight, and chooses to leave it there, diverting from her agenda. At the reflection meeting, Teacher Ana says that, at that moment, she thought that the poster would also be useful for correcting Task 2, so she did not remove it.

Another situation involving resources happened in Task 4. The students were supposed to assemble the solids designed, however none of the teachers had provided glue for that moment, which also triggered an unexpected situation due to the unavailability of the resource. Both teachers asked students who had glue to lend to their colleagues.

So, within Theme 1: Resources, we identified the three contingency triggering factors. We expected that the main factor within this theme was the resource, but we observed that the students and the teachers' actions also caused critical events.

3 In the transcriptions we will use TA for Teacher Ana and TB for Teacher Beatriz. Students are identified as EX, where X is a natural number and differs for each student. 


\section{Theme 2: Students Difficulties and Questions}

We present the Critical Events 3 and 4 that happened during Task 1 in Teacher Ana's class. In both events, the students had the same question: whether, when rotating a figure, we have a new geometric shape.

Critical event 3

\begin{tabular}{|l|l|l|}
\hline Section & Code identified & Triggering factor \\
\hline [13] E6: This is not a square. & & \\
\hline [14] E7: No, it is not a square. & & \\
\hline $\begin{array}{l}\text { [15] E6: It is not, because the "square position" is so straight, when you change it, } \\
\text { it is another figure. }\end{array}$ & \\
\hline $\begin{array}{l}\text { [16] TA: } \text { Ah, is it? It can only be a square if it is in the position... of the square? (makes } \\
\text { the drawing with her hands) }\end{array}$ & $\begin{array}{c}\text { Response to students' } \\
\text { ideas }\end{array}$ & \multicolumn{1}{|c|}{ Student } \\
\hline [17] E8: That's what I was going to ask. & & \\
\hline [18] TA: What do you think? & & \\
\hline
\end{tabular}

(Teacher Ana's classroom - Task 1 - 04/11/2019)

During the elaboration of Task 1, the teachers decided to approach the content of plane figures, whether suitable or not for that grade, as they intended to identify the students' previous knowledge of geometry. While the students carried out the proposed task, the teacher walked around the class observing the work done and the discussions that were taking place. In Critical Event 3 we observed that the contingency appears after a spontaneous response from students in a discussion about the task. If the teacher did not walk around watching the pairs, ignoring the dialogues, a situation like this could have been lost. However, based on E6's statement, the teacher questioned him and made him reflect on that situation (shift [16]). Also, Teacher Ana recognized and incorporated the student's idea into a discussion with the whole class (shift [18]).

We emphasize that contingency moments should not be seen as totally unexpected. As we reported in Critical Event 3, the initial objective of Task 1 , since its planning, was to identify previous knowledge. For this, the teachers added rotated figures to identify the most common errors among students. From the planning, the teachers could get prepared for contingency situations, which enabled fluid students' participation and discussion.

In Critical Event 4, the contingency is also triggered by a student, but unlike the previous one, it occurs due to a difficulty regarding one of Teacher Ana's questionings. Once again, the teacher was walking around the room when she noticed a student's difficulty.

\section{Critical Event 4}

\begin{tabular}{|c|c|c|}
\hline Section & Code identified & Triggering factor \\
\hline \multicolumn{3}{|l|}{ [19] TA: Tell me, E9, what's up, love? } \\
\hline \multicolumn{3}{|l|}{ [20] E9: Oh, teacher, I can't do it. I don't remember the geometric figures. } \\
\hline $\begin{array}{l}\text { [21] TA: Look, here are their names (points to the box with the names of the figures), } \\
\text { you can use it as a reference. For example, this one, do you think it's the square? } \\
\text { (referring to a parallelogram) }\end{array}$ & $\begin{array}{l}\text { Response to students' } \\
\text { difficulties }\end{array}$ & Student \\
\hline \multicolumn{3}{|l|}{ [22] E9: It looks like it, but... I don't think so. } \\
\hline \multicolumn{3}{|l|}{$(\ldots)$} \\
\hline [23] TA: Which geometric figures do you know? That you remember? & $\begin{array}{c}\text { Response to students' } \\
\text { difficulties }\end{array}$ & Student \\
\hline \multicolumn{3}{|l|}{ [24] E9: I know... ah, square. } \\
\hline \multicolumn{3}{|l|}{$\begin{array}{l}\text { [25] TA: Square. Which of these is a square? You've already put one here. (pointing } \\
\text { to the task) }\end{array}$} \\
\hline \multicolumn{3}{|l|}{ [26] E9: This is a square } \\
\hline \multicolumn{3}{|l|}{ [27] TA: And which... is there more? } \\
\hline \multicolumn{3}{|l|}{$\begin{array}{l}\text { [28] E9: Yes, but..., but they kind of droop, like this (makes the gesture with the } \\
\text { arms), you know? }\end{array}$} \\
\hline \multicolumn{3}{|l|}{ [29] TA: Because they are in other positions. } \\
\hline \multicolumn{3}{|l|}{ [30] E9: They are in other positions, so I don't think I can consider this a square. } \\
\hline [31] TA: But do you think that if I change the position of a figure, it changes it? & $\begin{array}{c}\text { Response to students' } \\
\text { difficulties }\end{array}$ & Student \\
\hline \multicolumn{3}{|l|}{ The student keeps silent. Apparently, she is going to answer, but then she gives up. } \\
\hline \multicolumn{3}{|l|}{ [32] TA: Oh, if we give a... I'll take an example for you here. } \\
\hline $\begin{array}{l}\text { The teacher goes to the table and picks up a quadrilateral that would be used in the } \\
\text { next task. She takes a square and brings it to E9. }\end{array}$ & Insight & Student \\
\hline
\end{tabular}




\begin{tabular}{|l|l|l|}
\hline \multicolumn{1}{|l|}{} & Availability of resources & \\
\hline [33] PA: This one... what figure is that? & & \\
\hline [34] E9: A square. & $\begin{array}{c}\text { Response to students' } \\
\text { difficulties }\end{array}$ & Student \\
\hline [35] TA: It is so. If I do this (she rotates the figure), will it change? & & \\
\hline [36] E9: No. & & \\
\hline [37] TA: It's still a square, isn't it? & & \\
\hline [38] E9: Yes. & & \\
\hline $\begin{array}{l}\text { [39] TA: So, regardless, if it is like this (starting position) or if it is like this (rotated } \\
\text { figure), it will be a square. Can you tell the difference between a square and a } \\
\text { rectangle? }\end{array}$ & & \\
\hline [40] E9: No. & Insight & Teacher \\
\hline [41] TA: Oh... & Availability of resources & Resource \\
\hline \begin{tabular}{l} 
The teacher goes back to her desk and takes a rectangle from the next assignment. \\
\hline
\end{tabular}
\end{tabular}

(Teacher Ana's classroom - Task 1 - 04/11/2019)

In this event, we identified the contingency codes in more than one moment. Besides, we observed a situation that fits neither the taxonomy hitherto proposed by Rowland, Thwaites, and Jared (2015) nor the KQ codes. Considering students as one of the triggering factors of the contingency moments, the researchers had determined three situations based on responses to the students' ideas. However, in Critical Event 4, student E9 does not bring an idea, but a difficulty, which creates this contingency in the classroom.

Thus, we suggest the development of a new code in the contingency dimension: the response to students' difficulties, which occurs due to a student's unexpected difficulty. In Critical Event 3, we highlighted that the teachers had planned for specific difficulties. However, what we observed in the dialogue between Teacher Ana and E9 was something unexpected, hence the contingency situation.

Regarding the contingency moments caused from this, we observed that the teacher can respond in three different ways. By: (1) giving the answer straight away; (2) providing tips for a possible answer; or (3) answering with a new question.

In shifts [21], [23], [31] and [35] we observed Teacher Ana questioning the student in her own difficulties, giving examples for case (3). She does not give answers or tips, but she questions the student and leads her to reflect on her knowledge, so that she can establish the necessary connections autonomously. Through questioning, Teacher Ana also investigated misconceptions and even gaps in the student's education.

To illustrate cases (1) and (2) of possible reactions after contingency situations, we will use moments from Task 4, when the groups needed to assemble planned solids. One of the groups was failing to do it, and, when they asked Teacher Ana to help them, she assembled the whole solid by herself, which would represent case (1). On the other hand, still in Task 4, a group was not able to find something from the daily life that looked like solid and Teacher Ana, instead of answering straight away, provided tips for a possible answer such as "A housewife knows it. To decorate the house....", illustrating case (2).

We realized that each reaction of the teacher somehow interferes in the progress of the class and the students' construction of reasoning. The more information the teacher offers, the lower the level of complexity and, consequently, the student's reflection and interpretation.Still on Critical Event 4, which highlights the dialogue between Professor Ana and E9, we see that in two moments, the teacher has an insight and decides to use the resources available, which had been developed to be used in Task 2. However, Teacher Ana realized that this was an opportunity to help the student through the resources. In this case, we have students as factors that trigger contingency. However, we identified that they are not the only ones to be held responsible for that, since this factor (students) directly interferes in the other factors (resources and teacher), through the availability of the resource (cut out plane figures) and the teacher's insight.

Finally, we present another critical event that addresses students' questioning.

Critical Event 5

\begin{tabular}{|l|c|c|}
\hline Section & Code identified & Triggering factor \\
\hline [42] E10: Teacher, don't you have a car called Prisma? & & \\
\hline [43] TA: Yes. & & \\
\hline [44] E10: So, you mean they have equal sides? & & Student \\
\hline $\begin{array}{l}\text { [45] TA: I don't know what their definition was to name the car Prisma (prism); but,, Response to students' } \\
\text { is it the only thing that prism means? Do we have only that prism? }\end{array}$ & \begin{tabular}{l} 
ideas \\
\hline [46] E10: There are others.
\end{tabular} & Insight \\
\hline $\begin{array}{l}\text { [47] TA: There must be others, right? There's a... stone called... let's see what we } \\
\text { have as a prism. }\end{array}$ & Teacher \\
\hline
\end{tabular}

(Teacher Ana's classroom - Task 3 - 05/03/2019) 
In this case, we note that from the discussion on Task 3, a student has an idea about the nomenclature "prism". Teacher Ana, in responding to the student's idea, recognizes it and incorporates it into the classroom discussion. In this sense, there is also an insight when the teacher decides to research the term "prism" and discuss the results found on the internet with the students.

We identified that, once again, the contingency triggered by one factor (students) ends up directing a new contingency situation with interference from another factor (teacher). Thus, the analyses carried out in theme 2 highlight the students' influence in contingency situations, whether due to an idea, questioning or difficulty, and how this interference deviates from the planned agenda and causes other contingency moments.

\section{Theme 3: Correction of Tasks}

In the moments of task correction, several contingency events took place. Some of them coming from the teachers, others from the students. The events that we will discuss on this topic were in Task 3.

While the students were working on the task, Teacher Beatriz was looking at the resolution strategies. She noticed that one of the groups had numbered the rows of the characteristics and assigned a letter to each column that contained the geometric solids. Thus, in an insight, the teacher decided to carry out the correction in that way, aiming to facilitate the comparison between the rows and the columns.

This caused a deviation from the schedule planned, however the correction was still very confusing, as students were confused with the letters with similar sound. Therefore, in another insight, Teacher Beatriz began to represent the letters in the Brazilian sign language LIBRAS, asking a student to put the answers on the board. Thus, doubts with some letters (such as B and D) were alleviated.

In Teacher Ana's office, we observed another type of situation caused by a student. Throughout the correction, the student realized that one of the characteristics that the teacher had corrected was in fact incorrect. Thus, his questioning during the correction generated a contingency moment, as we describe in Critical Event 6.

Critical Event 6

\begin{tabular}{|l|c|c|}
\hline Section & Code identified & Triggering factor \\
\hline $\begin{array}{l}\text { [48] E10: Teacher, there (points to the blackboard), where there is only one base... } \\
\text { the cone also has only one base and is not a pyramid. }\end{array}$ & & \\
\hline [49] TA: The cube? & & \\
\hline [50] E10: The cone. & & Student \\
\hline $\begin{array}{l}\text { [51] TA: Yes, it is true (goes to the blackboard to write), "pyramids and the cone"... } \\
\text { well remembered, E11. You'll get a score. }\end{array}$ & $\begin{array}{r}\text { Response to } \\
\text { students' ideas }\end{array}$ & \\
\hline
\end{tabular}

(Teacher Ana's classroom - Task 3 - 05/03/2019)

The contingency was triggered by the student when responding spontaneously about the correction. Teacher Ana recognized and paid attention to what the student had said, incorporating it into the discussion and congratulating the student.

These events reported dialogues during task correction and encouragement for student participation. They exposed their results and questions, which generated unexpected situations. Even observing the students during the development of the tasks, the teachers could not predict what would happen in the correction, but they did allow the students to participate and divert from the planned agenda to include the students' responses.

\section{DISCUSSION AND ANALYSIS OF RESULTS}

As in the results, the analysis will be focused on the contingency dimension. We resume its definition as a dimension of KQ that addresses the teacher's ability to respond convincingly to unpredictable situations (Rowland, 2013). Although those situations are not planned, we reaffirm the fundamental role of planning, since, based on it, teachers can identify the main errors and even possible ideas that will arise in the classroom. Furthermore, what defines the contingency dimension is not the unexpected, but the teacher's ability to resolve these situations clearly and precisely.

The codes that make up the contingency dimension are respond to students' ideas, deviation from the agenda, teachers' insight and (in)availability of resources. Rowland, Thwaites, and Jared (2015), when discussing specifically about the contingency dimension, determined factors that trigger those contingency moments, which are directly related to the dimension codes. Those factors would be the students, the teachers themselves and the resources, corresponding to the codes mentioned above, except for the deviation from the agenda. However, this code appears as a consequence of the others, since the contingency itself is something outside the planned agenda.

In the results, all of those codes were identified. When discussing the (in)availability of resources, we highlight even more the planning and preparation needed before using any resource in the classroom. In addition, we observed that when using a certain resource, the teachers need to get organized by planning additional or extra resources (such as the adhesive tape needed to stick the poster), which serve as a basis for the use of the resource planned. Thus, even though materials and resources enhance learning, we need to reflect on how, where and why we will use them (or not) and what will be the other necessary accessories for its proper functioning (Costa \& Lins, 2010). 
On the other hand, resources that were not planned may be available at some point. It is also up to the teachers to reflect on whether it is appropriate or not to incorporate the resource in their class, which is related to the insight in the classroom, as we showed in the critical events of this research. The decisions made in the classroom, which modify and divert from the planned agenda, are in line with Schön's theory (2000) and what he calls "Reflection in Action", that is, a reflection that occurs during the class and causes a reformulation of the action at that moment, the teacher's insight.

In the data, we identified this insight derived from a student's difficulty linked to an available resource. Thus, we emphasize that there is no strict limit between codes, which often overlap and can be identified concurrently (Rowland, Huckstep, \& Thwaites, 2005).

Finally, we analyzed the response code to the students' ideas and the knowledge it mobilized. Within the contingency dimension, this was the most identified code, which determines students as the main triggering factor for contingency moments. This was also identified in Rowland, Thwaites, and Jared (2015), since the teacher is relating to humans and it is not possible to predict the reaction of each of them. Thus, the contingency can be caused by the teachers themselves or by an external agent, which may be the students or the resources (which can be adjusted and are less unpredictable than the students).

We found those responses to students' ideas based on spontaneous answers from students, which again demonstrates the unpredictability of those moments of students' discussion with each other, or between student and teacher. Most of the times the teachers recognized the idea, incorporating it into the discussion, making the student an active agent in the teaching and learning process.

On the other hand, we suggest the development of a new code in the contingency dimension, which also meets KQ, a new theoretical tool still under development, allowing for changes and improvements from new research works (Rowland, Huckstep, \& Thwaites, 2005). This new code would be responses to students' difficulties, which is different from the responses to the ideas, given that in those cases there is no suggestion or concern on the part of students, but rather a difficulty that needs to be overcome.

In planning tasks and/or classes, the teacher plans for common mistakes that appear throughout the development/execution of the task. However, it is possible to identify other errors and difficulties the teacher is not expecting. In this situation, it is necessary that the teacher knows how to resolve and, consequently, respond to that in a convincing way, a skill of the contingency dimension. Therefore, when a student triggers a contingency moment, it can be in the form of responding to a student's idea; or responding to a student's difficulty. The teachers can react to students' difficulties in three different ways: (1) by giving them the answer straight away; (2) by providing tips for a possible answer; or (3) by answering through a new question.

Stein and Smith (1998) also discuss those teachers' reactions upon the students' questions and difficulties. They point out that when students pressure the teacher and the teacher ends up answering or indicating steps to perform tasks, the level of complexity of the task is reduced. Thus, the task is no longer investigative, as it loses the challenging and logical aspects, being restricted to a sole application of procedures (Stein \& Smith, 1998). Examples like these were also identified in the results of this article and refer to types (1) and (2).

On the other hand, when analyzing the sections and critical events that relate to type (3), we observed that the teacher tries to help students from their previous knowledge. In this way, students are encouraged to reflect on their own task and to develop reasoning and mathematical thinking skills (Stein \& Smith, 1998).

In the results, we realized that the main difficulty was the identification of geometric figures. This difficulty has already been discussed in other works, such as Passos's (2000), who identified that teachers from the early years of education also had this difficulty when observing rotated figures. Thus, she reports that "when they [the teachers] try to teach geometry to their students, they find it very difficult, both theoretically and methodologically, which can compromise the students' learning process" (Passos, 2000, p. 317).

Thus, once again we highlight planning as an essential part for the teacher to know the content, getting prepared for possible questions from students or for the use of possible resources that assist in the development of geometry in the classroom.

From these discussions, we expanded the studies on the contingency dimension addressed in Rowland, Thwaites, and Jared (2015), as shown in Figure 6.

We elaborated Figure 6 with emphasis on the expansion of studies on the contingency dimension. Through this research, we have highlighted KQ as a theoretical analysis tool still under development, as new results can be identified with the development of other studies. Although the three triggering factors of the contingency were the same as those of Rowland, Thwaites, and Jared (2015), we observed a situation that the taxonomy did not contemplate: the students' difficulties. In addition, we identified that teachers can react in three different ways when faced with this situation. These results may indicate new codes or a reorganization in relation to dimensions. 


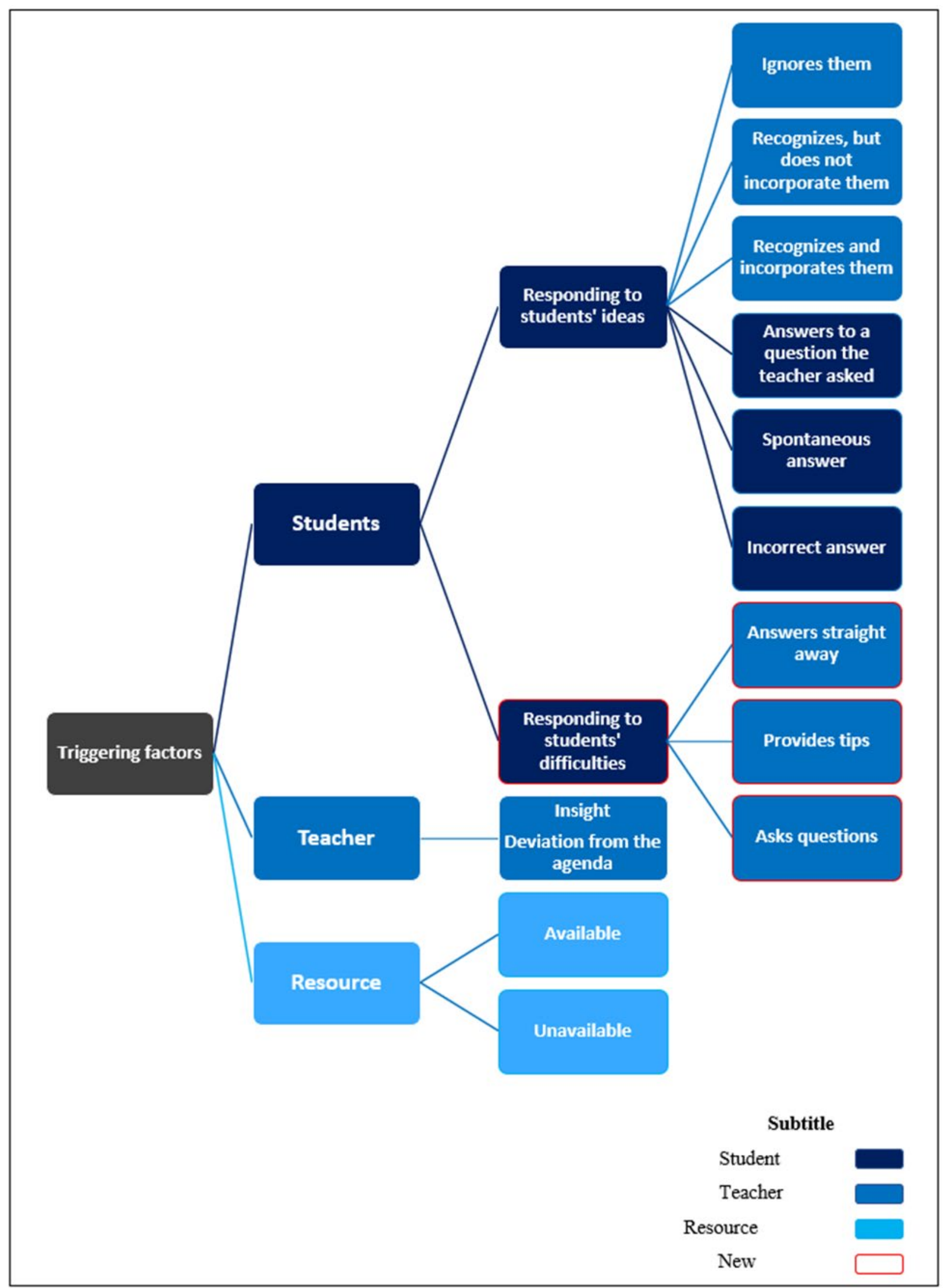

Figure 6. Expansion of the taxonomy on contingency triggering factors 


\section{CONCLUSION}

When investigating the professional teaching knowledge mobilized throughout the development/execution of geometry tasks in the classroom, we identified the four dimensions of the KQ. However, we chose to focus the analysis on the contingency dimension, which stands out in the teachers' practice and their ability resolve unplanned moments.

The four codes that make up this dimension were found in the research data, which indicates the constant mobilization of knowledge related to contingency. In the development/execution of the tasks, the teachers diverted from the agenda at different times. This was caused by available resources (or not), by insights and by the students' own ideas and difficulties, which is directly related to the dimension codes.

In previous research works, three contingency triggering factors (student, teacher and resources) and their consequences were determined, which could be expanded through the analysis of this research. This expansion contributed to the consolidation and procedural development of KQ. However, recognizing KQ as a theoretical analysis tool still under development, we know that other factors can be identified from new research.

The mobilization of teaching knowledge in the classroom is related to the practice and, consequently, contingency is a dimension that stands out in practice. In this way, teachers' insight would be more common in experienced teachers, as this knowledge is directly mobilized in practice. However, we look for an initial training that contemplates contingency situations through collaboration, inserting the teachers in universities, in order to overcome the dichotomy between theory and practice. The results of this research can be discussed in education processes to discuss and develop strategies collaboratively, helping teachers on how to act in contingency moments, without reducing the complexity of investigative tasks.

As we highlight the triggering factors of contingency, we present the influence of students, resources, and the very teachers' ideas in the development of the class, which can modify the planned agenda. Knowing these factors and the teachers' main reactions to situations, allows them to be prepared to face the unexpected skilfully. In fact, this is what we expect as we study the contingency dimension of KQ: to achieve the ability to respond to unforeseen situations convincingly. Therefore, we reiterate the fundamental role of planning. Expanding the triggering factors and/or their consequence demonstrates the wealth of possibilities within the classroom, which, in the future, may suffer other interferences. Here, we point out those that have been identified so far and encourage the production of further research on this topic.

In terms of future research, the teachers' insights can be related to Schön's theory (2000), which, although not theoretically discussed in this article, stood out when we approached the teachers' reflection on their classes, either during the action or after the action. We reiterate that this article is part of a multipaper dissertation including analysis presented in two articles, the first one focusing on planning, and this one, which is the second article. Thus, we indicate future research that could investigate the professional knowledge of teachers who teach mathematics in relation to the process of reflection on practice, with KQ and Schön's studies (2000) as theoretical assumptions.

\section{ACKNOWLEDGEMENTS}

This study was financed in part by the Coordenação de Aperfeiçoamento de Pessoal de Nível Superior - Brazil (CAPES) Finance Code 001.

\section{REFERENCES}

Ball, D., Thames, M. H., \& Phelps, G. (2008). Content knowledge for teaching: what makes it special? Journal of Teacher Education, 59(5), 389-407. https://doi.org/10.1177/0022487108324554

Borba, M. C., \& Araújo, J. L. (2019). Pesquisa qualitativa em Educação Matemática (6th ed.). Belo Horizonte: Autêntica.

Brasil. Ministério da Educação. (2018). Base Nacional Comum Curricular. Brasília, DF. Retrieved on 11 March 2020 from http://basenacionalcomum.mec.gov.br/images/BNCC_El_EF_110518_versaofinal_site.pdf

Browning, C., et al. (2014). Mathematical Content Knowledge for Teaching Elementary Mathematics: a Focus on Geometry and Measurement. The Mathematics Enthusiast, 11(2), 333-384.

Costa, M. L. C. da, \& Lins, A. F. (2010). Trabalho colaborativo e utilização das tecnologias da informação e comunicação na formação do professor de Matemática. Educação Matemática Pesquisa, 12(3), 452-470.

Passos, C. L. B. (2000). Representações, interpretações e prática pedagógica: a geometria na sala de aula (Doctoral Thesis). Universidade Estadual de Campinas, Campinas, SP.

Powell, A. B., Francisco, J. M., \& Maher, C. A. (2004). Uma Abordagem à Análise de Dados de Vídeo para Investigar o Desenvolvimento de Idéias e Raciocínios Matemáticos de Estudantes. Bolema, 21, 81-140.

Rowland, T. (2013). The Knowledge Quartet: the genesis and application of a framework for analysing mathematics teaching and deepening teachers' mathematics knowledge. Sisyphus: Journal of Education, 1(3), 15-43. https://doi.org/10.25749/sis.3705

Rowland, T., Huckstep, P., \& Thwaites, A. (2005). Elementary Teachers' Mathematics Subject Knowledge: the Knowledge Quartet and the Case of Naomi. Journal of Mathematics Teacher Education, 8 (3), 255-281. https://doi.org/10.1007/s10857-005-0853-5 
Rowland, T., Thwaites, A., \& Jared, L. (2015). Triggers of contingency in mathematics teaching. Research In Mathematics Education, 17(2), 74-91. https://doi.org/10.1080/14794802.2015.1018931

Schön, D. A. (2000). Educando o profissional reflexivo: um novo design para o ensino e a aprendizagem. Porto Alegre: Artmed.

Shulman, L. S. (1986). Those who understand: Knowledge growth in the teaching. Educational Researcher, 15(2), 4-14. https://doi.org/10.3102/0013189X015002004

Shulman, L. S. (1987). Knowledge and teaching: Foundations of the new reform. Harvard Educational Review, 57(1), 1-22. https://doi.org/10.17763/haer.57.1.j463w79r56455411

Stein, M. K. \& Smith, M. S. (1998). Mathematical tasks as a framework for reflection: from research to practice. Mathematics Teaching in the Middle School, 3(4), 268-275. https://doi.org/10.5951/MTMS.3.4.0268 